\title{
The Relationship between Risk and Expected Return in Europe
}

\author{
Ángel León \\ (University of Alicante) \\ Juan Nave \\ (University of Castilla La Mancha) \\ and \\ Gonzalo Rubio \\ (University of the Basque Country)
}

January 2005

Keywords: risk-return trade-off, hedging component, MIDAS, conditional variance

JEL classification: G12, C22

The authors acknowledge financial support from Fundación BBVA research grant 1-BBVA 00044.32115466/2002. The contents of this paper are the sole responsibility of the authors. Corresponding author: Gonzalo Rubio, Facultad de Ciencias Económicas, Universidad del País Vasco, Avda. del Lehendakari Aguirre 83, 48015 Bilbao, Spain (jepruirg@bs.ehu.es) 


\begin{abstract}
We employ MIDAS (Mixed Data Sampling) to study the risk-expected return trade-off in several European stock indices. Using MIDAS, we report that, in most indices, there is a significant and positive relationship between risk and expected return. This strongly contrasts with the result we obtain when we employ both symmetric and asymmetric GARCH models for conditional variance. We also find that asymmetric specifications of the variance process within the MIDAS framework improve the relationship between risk and expected return. Finally, we introduce bivariate MIDAS and find some evidence of significant pricing of the hedging component for the intertemporal riskreturn trade-off.
\end{abstract}




\section{Introduction}

Numerous papers have investigated the relationship between expected excess return and conditional variance of aggregate wealth. Of course, this comes as no surprise given that this fundamental trade-off is the basic foundation of financial economics. Merton (1973) shows that when the investment opportunity set is constant or, alternatively, rates of returns are independent and identically distributed there is a positive relationship between expected excess return and conditional variance:

$$
E_{t}\left(R_{W t+1}\right)=\left[\frac{-J_{W W} W}{J_{W}}\right] \operatorname{Var}_{t}\left(R_{W t+1}\right)=\gamma \operatorname{Var}_{t}\left(R_{W t+1}\right)
$$

where $J($.$) is the indirect utility function with sub-indices indicating partial derivatives,$ $W_{t}$ is aggregate wealth, $E_{t}\left(R_{W t+1}\right)$ is the conditional expected excess return of aggregate wealth between time $t$ and $t+1, \operatorname{Var}_{t}\left(R_{W t+1}\right)$ is the conditional variance of aggregate wealth, and $\left[-J_{W W} W / J_{W}\right]$ is a measure of relative risk aversion which we denote as $\gamma$. Given risk aversion among investors, we of course expect a positive relationship between expected return and risk.

On the other hand, Merton (1973) shows that when the investment opportunity set is stochastic and returns are not independent and identically distributed the dynamic relationship between expected return and risk includes additional terms to recognize the hedging behavior of investors regarding unfavorable movements in the opportunity set. In this case, assuming that the opportunity set is completely characterized by one state variable, we write the model as:

$$
\begin{aligned}
E_{t}\left(R_{W t+1}\right) & =\left[\frac{-J_{W W} W}{J_{W}}\right] \operatorname{Var}_{t}\left(R_{W t+1}\right)+\left[\frac{-J_{W Z}}{J_{W}}\right] \operatorname{Cov}_{t}\left(R_{W t+1}, R_{Z t+1}\right) \\
& =\gamma \operatorname{Var}_{t}\left(R_{W t+1}\right)+\lambda \operatorname{Cov}_{t}\left(R_{W t+1}, R_{Z t+1}\right)
\end{aligned}
$$

where $Z_{t}$ is the state variable that describes the stochastic behavior of the investment opportunity set and motivates the hedging behavior of investors. 
Surprisingly, given the importance of the topic, it has proved difficult from an empirical perspective to find a positive relationship between expected return and risk. French, Schwert and Stambaugh (1987), Campbell and Hentschel (1992) and Guo and Whitelaw (2003) find a positive but non-significant relationship. On the other hand, a number of authors find a negative and significant relationship. Among them, we should mention Campbell (1987), Nelson (1991), Glosten, Jagannatham and Runkle (1993) and Lettau and Ludvigson (2003). In related papers, Harvey (2001) argues that the sign of the empirical evidence depends on the exogenous predictors employed in conditional asset pricing models tested, and Brandt and Kang (2004) find different results depending upon whether unconditional or conditional correlations are used. All these papers employ US data. Evidence from other countries is rare and inconclusive. Guo (2004) uses daily price indices obtained from Morgan Stanley Capital International to construct realized volatility for 18 individual stock markets, including the US, and the world market portfolio. He finds that volatility does not forecast excess returns in most countries, but it becomes a significant predictor when combined with the US consumption-wealth ratio proposed by Lettau and Ludvigson (2001). Finally, Alonso and Restoy (1995) find a positive and non-significant relationship for the Spanish Stock Exchange, and make the interesting point that the magnitude of the relationship depends on the relative value of equity holdings by Spanish investors.

There are two approaches in the relevant literature that seek to explain this disturbing and intriguing empirical evidence. To understand the first approach is must be noted that all the key papers mentioned above analyze the risk-return relationship in the context of expression (1), without recognizing the potential stochastic behavior of the opportunity set as described by state variables other than aggregate wealth. On pointing out this potential deficiency which characterizes this line of research, Scruggs (1998) reports some striking results on the decomposition of the expected excess market return into risk and hedge components. Assuming that long-term government bond returns are the hedging instrument for covering unfavorable movements in the opportunity set as described by short-term interest rates, he estimates equation (2) using a bivariate exponential GARCH model and finds that the coefficient of relative risk aversion is positive and statistically significant. The coefficient changes from an insignificant 0.86 under expression (1) to a highly significant 10.6 when estimating the intertemporal 
model represented by $(2)^{1}$. Scruggs argues convincingly that the simple risk-return trade-off obtained from conditional single-factor models may be biased downward due to the omission of relevant state variables from the conditional market risk premium equation given by (2). This suggests that the first potential explanation of the weak riskreturn trade-off found in literature is due to the misspecification of the asset pricing model.

The second explanation is related to the fact that the conditional variance of the market is not observable and must be filtered from past returns. Therefore, we should introduce flexible techniques able to adequately predict future realized variance. Ghysels, SantaClara and Valkanov (2003, 2004a) (GSV hereafter) introduce Mixed Data Sampling (henceforth MIDAS) under which the variance estimator forecasts the monthly variance with an optimal and flexible weighted average of lagged daily squared returns. In other words, this estimator involves data sampled at different frequencies as well as the possibility of introducing various past data window lengths, where the weights of past observations are parameterized by a flexible function. Under the perspective of equation (1), and for US data, GSV (2004a) find a significant coefficient of relative risk aversion of 2.6 between 1928 and 2000. Hence, the second potential explanation of the above finding regarding the relationship between risk and return is associated with the problem of estimating the dynamics of the conditional variance.

The objective of this work is to study the relationship between risk and expected returns, using European data as an alternative to the well known behavior of US data, to understand which of the two potential explanations discussed above better explains the basic risk-return trade-off. In other words, we want to analyze whether the weak relationship found previously in literature is related to the misspecification of the theoretical model, to the imposing of the wrong dynamics for the conditional variance or to both.

The rest of this paper is structured as follows. Section 2 describes the data set employed in the research. Section 3 discusses the evidence under the GARCH framework, while Section 4 presents MIDAS and reports results with symmetric shocks. Section 5 extends

\footnotetext{
${ }^{1}$ See also the quite convincing recent evidence reported by Brennan, Wang and Xia (2004) in favor of the intertemporal asset pricing model in explaining the cross-sectional variation of expected returns.
} 
the results to asymmetric shocks, and Section 6 explores the intertemporal asset pricing model under bivariate MIDAS. Section 7 concludes.

\section{Data}

We have daily stock exchange indices from Eurostoxx50, CAC (France), DAX (Germany), Ibex-35 (Spain) and FTSE100 (United Kingdom) from January 1988 to December 2003. These data allow us to calculate daily and monthly returns for the same period. We also have daily total indices of long-term government bond indices for France, Germany and the United Kingdom spanning the same sample period. From 1988 to December 1993 these indices were provided by the DataStream Benchmark bond indices. They consist of the most liquid government bond indices and follow the methods of the European Federation of Financial Analysts ${ }^{2}$. From January 1994 onwards, the bond indices are from Morgan Stanley Capital International. The Spanish long-term government bond index is the total index constructed daily since 1988 by the Bank of Spain ${ }^{3}$. As with equity data, we use these indices to calculate both daily and monthly total returns for government bonds ${ }^{4}$. In order to have overall European bond returns, we merely calculate the equally weighted bond portfolio returns from the four available European countries. The short-term risk-free monthly interest rates are provided by International Financial Statistics (IFS). For the United Kingdom and France we have the monthly yield on 3-month Treasury bills, while for Germany and Spain we use the money market rate ${ }^{5}$. As before, the overall European short-term rate is the equally-weighted average of the previous rates. The daily risk-free rate is constructed by assuming that the Treasury bill and money market rates remain constant within the month and suitably compounding them. Finally, equity and bond excess returns are calculated by the differences between equity or bond returns and the short-term risk-free rate. From now on, it should be understood that we employ excess returns.

\footnotetext{
${ }^{2}$ These data were kindly provided by Kevin Sheppard from the University of California at San Diego.

${ }^{3}$ We thank Juan Ayuso from the Bank of Spain for his help in obtaining this index.

${ }^{4}$ These are total returns in the sense that they reflect both changing prices and interest payments.

${ }^{5}$ We thank Hui Guo from the Federal Reserve Bank of St. Louis for providing us with these data.
} 


\section{The Risk-Return Trade-off under GARCH Specifications}

All previous models mentioned in the introduction have employed some form of conditional variance from the GARCH family. This is the most common approach used to study the risk-return relationship.

The mean equation to be estimated is given by expression (1) which may be written in the usual way as:

$$
E_{t}\left(R_{m t+1}\right)=\mu+\gamma \operatorname{Var}_{t}\left(R_{m t+1}\right)
$$

where $R_{m t+1}$ is the excess return on the market portfolio and $\mu$ a constant which should not be different from zero under a risk-free asset.

The simplest model we estimate is the GARCH-in-mean $(1,1)$ whose variance equation is given by:

$$
\operatorname{Var}_{t}^{\text {garch }}=\omega+\alpha \varepsilon_{m t}^{2}+\beta \operatorname{Var}_{t-1}^{\text {garch }}
$$

where $\varepsilon_{m t}=R_{m t}-\mu-\gamma \operatorname{Var}_{t-1}^{\text {garch }}$, and $\mu, \gamma, \omega, \alpha, \beta$ are parameters to be estimated.

Given the well known asymmetric response of the conditional variance to positive and negative shocks, we also estimate the EGARCH-in-mean $(1,1)$ model:

$$
\ln \operatorname{Var}_{t}^{\text {egarch }}=\omega+\beta \ln \operatorname{Var}_{t-1}^{\text {egarch }}+\alpha\left[\left|\eta_{t}\right|-\sqrt{2 / \pi}-c \eta_{t}\right]
$$

where $c$ is the parameter that captures the effects that asymmetric positive and negative shocks $\varepsilon_{m t}$ have on conditional variance, and $\varepsilon_{m t}=V_{t-1} \eta_{t}$ where $\eta_{t}$ is distributed as a normal random variable with zero mean and unit variance.

The results of estimating models (4) and (5) with monthly data from January 1989 to December 2003 for our five equity indices are reported in Table 1. In particular, this table contains the relative risk aversion coefficients for the $\operatorname{GARCH}(1,1)$ and 
EGARCH(1,1) models as well as the asymmetric response coefficient of the exponential model.

As expected given the previous empirical evidence, the results are very disappointing. When estimating the $\operatorname{GARCH}(1,1)$ the risk aversion coefficient is positive but not significantly different from zero in four of our five indices. The fifth coefficient is negative but statistically insignificant. When the $\operatorname{EGARCH}(1,1)$ is considered the results are, if anything, worse. Four out five risk aversion parameters are estimated to be negative, although not significantly different from zero. As usual, the relationship between risk and return seems to be very weak. The only reasonable coefficient is associated with Eurostoxx50. Also note that the asymmetric response coefficient reported in the last column of Table 1 is always negative and is statistically significant in four cases. Interestingly, this coefficient is not significantly different from zero for Eurostoxx50, where a very slight evidence of a positive risk-return trade-off is reported. This disturbing evidence might just reflect that GARCH in-mean models lack the power to find statistical significance for the risk aversion coefficient. This possibility is analyzed in the following section.

\section{The Risk-Return Trade-off under Symmetric MIDAS}

\subsection{The MIDAS Specification}

The general idea behind MIDAS is to employ mixed-frequency regressions. Suppose that a variable $R_{m t+1}^{(h)}$ is available once between $t$ and $t+1$ (say monthly) where this variable represents the excess return on an equity index over a horizon $h$ where $h$ is measured in trading days. In the case of monthly data, $h=22$, but of course it may be one week $(h=5)$, two weeks $(h=10)$ or any other horizon of interest for the researcher.

In our application below $R_{m t+1}^{(h)}$ is the monthly market excess return. We now consider the MIDAS regression proposed by GSV (2003):

$$
R_{m t+1}^{(h)}=\mu+\gamma \sum_{d=0}^{D} \omega(d ; k)\left(r_{t-d}^{(h)}\right)^{2}+\varepsilon_{m t+1}^{(h)}
$$


where $\left(r_{t-d}^{(h)}\right)^{2}$ is the lagged daily squared market excess returns associated with the predicting horizon of 22 trading days (the following month) which is assumed to be a measure of variance. The weight function is parameterized as:

$$
\omega(d ; k)=\frac{\exp \left(k_{1} d+k_{2} d^{2}+\ldots .+k_{Q} d^{Q}\right)}{\sum_{i=0}^{D} \exp \left(k_{1} i+k_{2} i^{2}+\ldots .+k_{Q}{ }^{i} Q\right)}
$$

where typically $d$ is measured in time elapsed as a lag operator (days in our application). This is called "exponential Almon lag" because of the Almon lags from the distributed lag models ${ }^{6}$. This function turns out to be quite flexible and, as discussed in our empirical application below, can take various shapes with only a few parameters. In the application of GSV (2004a) estimating the relationship between risk and return, in GSV (2004b) when predicting volatility against a family of competing models and in Ghysels, Santa-Clara, Sinko and Valkanov (2004) when extending the study of the riskreturn trade-off to various specifications of lag structures to parameterize regressions parsimoniously, the functional form (7) is characterized by only two parameters $k_{1}$ and $k_{2}$. In should be noted that expression (7) guarantees that the weights are positive, which ensures that the conditional variance is also positive, and add up to one ${ }^{7}$.

As pointed out by GSV (2004b), regression (6) has three important features when compared to other models relating conditional variance and expected return, or to alternative models of predicting conditional variance. First, the return measure on the left-hand side, $R_{m t+1}^{(h)}$, and the variables on the right-hand side, $\left(r_{t-d}^{(h)}\right)^{2}$, can be sampled at different frequencies. Second, the polynomial lag parameters, $\omega(d ; k)$, are parameterized to be a function of $k$, thereby allowing for a longer history without augmenting the number of parameters. Note that the available applications only employ two parameters producing all potential shapes of interests in the weighting schemes.

\footnotetext{
${ }^{6}$ See Judge, Griffith, Hill, Lutkepohl and Lee (1985), and the discussion in GSV (2003), GSV (2004b) and Ghysels, Santa-Clara, Sinko and Valkanov (2004).

${ }^{7}$ GSV (2004b) also employ the Beta function characterized by only two parameters as the weight function. The flexibility of the Beta function is well known and it has similar properties to the exponential Almon lag.
} 
Third, MIDAS regressions do not exploit an autoregressive scheme, so that $\left(r_{t-d}^{(h)}\right)^{2}$ is not necessarily related to lags of the left-hand side variable.

There have been two relevant applications of MIDAS regression to financial data. GSV (2004a) shows a significantly positive relation between risk and return in the US stock market at monthly frequencies. They show that their finding is robust in sub-samples and to asymmetric specifications of the variance dynamics. They employ lagged daily squared returns as a measure of variance. In a second empirical exercise, GSV (2004b) consider several MIDAS regression models to predict stock market volatility. The models differ in the specifications of regressors as measures of variances. In particular, they consider squared returns, absolute returns, realized volatility, realized power (the sum of high frequency absolute returns), and return ranges. Moreover, the models differ in the use of daily or intra-daily (five minute) data, and in the length of the past history included in the forecasts. Interestingly, they find that the daily realized power (with 5minute absolute returns) is the best predictor of future volatility. Ghysels, Santa-Clara, Sinko and Valkanov (2004) make use of this evidence and find that the relationship between conditional mean and conditional variance is positive and significant even at horizons of one, two, and three weeks. Although the proxy of expected returns is known to be noisy at shorter horizons, forecasts of conditional variance are more accurate at shorter horizons. This may explain their positive results. Also, the positive trade-off between risk and return is present using all predictors of variance, and they find very little difference regardless of whether they use squared returns, absolute returns, ranges, or realized power all at daily frequencies. As they point out, this latter result and the evidence reported in their predicting volatility paper taken together suggest that these variables forecast a component of variance that does not receive compensation in expected returns. In any case, it seems that the MIDAS framework is extremely useful for studying the relationship between expected return and risk. In this sense, our paper extends their evidence to alternative equity indices to provide a test of robusteness.

\subsection{The Risk-Return Trade-off in Europe under a Symmetric MIDAS Specification}

In this sub-section, our empirical exercise with five European equity indices test the simple relationship between expected market excess return and conditional variance at 
monthly frequencies as given by expression (3). In this context the mean equation in the MIDAS regression framework can be written as:

$$
R_{m t+1}=\mu+\gamma \operatorname{Var}_{t}^{\text {midas }}\left(R_{m t+1}\right)+\varepsilon_{m t+1}
$$

The MIDAS estimator of the conditional variance of monthly excess returns, $\operatorname{Var}_{t}\left(R_{m t+1}\right)$, is based on past daily squared excess return data:

$$
\operatorname{Var}_{t}^{\text {midas }}\left(R_{m t+1}\right)=22 \sum_{d=0}^{D} \omega\left(d ; k_{1}, k_{2}\right) r_{m t-d}^{2}
$$

where $\omega\left(d ; k_{1}, k_{2}\right)$ is the weight given to the squared excess return of day $t$ - $d$, and is given by:

$$
\omega\left(d ; k_{1}, k_{2}\right)=\frac{\exp \left(k_{1} d+k_{2} d^{2}\right)}{\sum_{i=0}^{D} \exp \left(k_{1} i+k_{2} i^{2}\right)}
$$

As above, we use the lower case to denote daily returns and the upper case to denote monthly returns. Hence, $r_{t-d}$ are the daily excess return $d$ days before date $t$. The factor 22 enables variance to be expressed in monthly units assuming that there are typically 22 trading days in a month. The relationship between expected return and risk is tested by estimating equations (8) and (9) simultaneously.

It is important to note that the weights given by (10) are not only positive, which makes the conditional variance necessarily positive as desired, but also add up to one. Moreover, this functional form may produce a wide and useful variety of shapes assigned to past daily squared returns depending upon the values of the two parameters. In order to analyze the potential shapes we introduce the quadratic function $f(d)=k_{1} d+k_{2} d^{2}$ with derivatives given by $f^{\prime}=k_{1}+2 k_{2} d$ and $f^{\prime \prime}=2 k_{2}$. Equating the first derivative to zero, we have that $d^{*}=-k_{1} / 2 k_{2}$ will be either the maximum or minimum of the function depending on the sign of the second derivative. Moreover, 
$f(0)=0$, and we define $\bar{d}$ as $d\left(k_{1}+k_{2} d\right)=0 \Rightarrow \bar{d}=-k_{1} / k_{2}$. We analyze four cases represented in Figure 1. In the first case $k_{1}<0$ and $k_{2}>0$, which implies that $d^{*}>0, \bar{d}>d^{*}$ and $f^{\prime \prime}>0$ so that the quadratic function reaches a minimum at $d^{*}$ as shown in the first graph on the left-hand side of case 1 . The functional form assumed for the weights is exponential, and therefore the weight function is $\omega(d)=e^{f(d)} / \sum_{d} \omega(d)$ which has the ascending form to the right of $d^{*}$. From an economic point of view, this case does not make much sense. It is not reasonable to think that remote days should receive larger weights when forecasting variances, and this is exactly what happens when $k_{1}<0$ and $k_{2}>0$. In the second case, $k_{1}>0$ and $k_{2}<0$, which implies that $d^{*}>0, \bar{d}>d^{*}$ and $f^{\prime \prime}<0$ so that the quadratic function reaches a maximum at $d^{*}$ as shown in the first graph at the left-hand side of case 2 . The exponential weight function now has a hump-shaped pattern with relatively fast increasing weights and gradually declining weights as we move far away from the beginning of the forecasting date. This case seems to be plausible from an economic point of view. The third case, in which $k_{1}<0$ and $k_{2}<0$, implies that $d^{*}<0, \bar{d}<d^{*}$ and $f^{\prime \prime}<0$ reaching a maximum at a negative $d^{*}$. This is probably the most reasonable case for which we obtain a slowly declining function of the lag length. Finally, the fourth case with $k_{1}>0$ and $k_{2}>0$, implies that $d^{*}<0, \bar{d}<d^{*}$ and $f^{\prime \prime}<0$ reaching a minimum at a negative $d^{*}$ is not economically relevant. This analysis suggests that the second parameter, $k_{2}$, associated with the quadratic variable in the weight function, plays a key role in the weighting scheme since a declining weight is guaranteed as long as $k_{2} \leq 0$. It is also important to note that the rate of decline determines how many lags are included in MIDAS regression. Since the parameters are estimated from the data, once the functional form of $\omega\left(d ; k_{1}, k_{2}\right)$ is specified, the lag length selection is purely data driven.

This analysis implies that the weights of the MIDAS estimator are well constructed to capture the dynamics of the conditional variance. The more weight is assigned to the distant past, the more persistence is reflected in the variance process. At the same time, the weighting scheme also controls for the amount of data needed to estimate conditional variance. Of course, if the weight function decays slowly, a large number of observations will be employed and the measurement error of the estimation will be low. 
As pointed out by GSV (2004a) this suggests some tension between proper incorporation of the dynamics of variance and the minimizing of measurement errors.

GSV (2003) consider a class of estimators which maximizes an objective function that depends on the data and sample size, and includes maximum likelihood, nonlinear least squares and generalized method of moments. They show that the three estimators are consistent and asymptotically normal under suitable regularity conditions well established in the relevant literature. In our empirical application, we employ the variance estimator (9) with the weight function (10) in the risk-return relationship given by (8). We jointly estimate the parameters $k_{1}, k_{2}, \mu$ and $\gamma$ by nonlinear least squares and the corresponding standard errors are obtained as described by Judge, Griffith, Hill, Lutkepohl and Lee (1985) and Greene (1998).

Table 2 contains the results for the five European stock indices between 1988 and 2003. Depending upon the country, we employ data between 248 and 253 days as the maximum lag length, which means that the actual test of the risk-return trade-off with monthly data goes from January 1989 to December $2003^{8}$. The estimated risk aversion coefficient $\gamma$ is between a positive and significant 4.81 for Eurostoxx 50 and a positive but not significant 1.53 for the United Kingdom. The rest of the risk aversion coefficients are positive and slightly higher than two but only marginally significant. In any case, there is a clear improvement from the weak and even negative relationship found under the GARCH specification ${ }^{9}$.

The estimates of $k_{1}$ and $k_{2}$ are reported although they have no economic interpretation. However, they determine the shape of the polynomial lags $\omega\left(d ; k_{1}, k_{2}\right)$ which are of clear significant economic interest. For example, it should be noticed that $k_{2}$ is negative in all five cases. We report what fraction of the polynomial lags is placed on the first five daily lag, daily lags 6 to 30, and lags beyond the first thirty days. As mentioned above, weights are available as fractions because they have been normalized

\footnotetext{
${ }^{8}$ Daily data for 1988 is employed to forecast the market variance for the first monthly intervals. There are between 248 and 253 trading days for our European indices during 1988. These are maintained for the corresponding country throughout the estimation period.

${ }^{9}$ It is interesting to point out the recent evidence reported by Santa-Clara and Yan (2004) that the average risk premium that compensates investors for the risks implicit in option prices is about twice the premium required to compensate the realized volatility.
} 
to add up to one. In Figure 2, we plot the estimated weights of the conditional variance on the lagged daily squared returns for the full sample. The weights present quite different shapes depending on the country. The slowly declining weight of Eurostoxx 50 is similar to that reported by GSV (2004a) for the US market. It takes almost 200 days to accurately forecast the variance of this index. This suggests a strong persistence in variance. A similar result is observed for Germany. However, France, Spain and especially the United Kingdom are characterized by very pronounced hump-shaped weights, and little persistence in variance. They have a maximum close to the forecasting date and a relatively quick declining shape afterwards. For these equity indices, between two and three months of daily returns are sufficient to reliably estimate the variance. These shapes are reflected in the percentage reported in Table 2. Eurostoxx50 and Germany have 65.1 and 72.3 percent of the weights allocated to days beyond 30 trading days respectively. A very different picture emerges for France, Spain and, of course, for the United Kingdom.

It seems clear that the success of MIDAS compared to GARCH lies in the additional statistical power that mixed-data frequency regressions get from the use of daily data in estimating conditional variance. In the variance equation, MIDAS estimates two parameters rather than three as GARCH does and employs many more observations to forecast market variance. At the same time, the shape of the weight function in the GARCH family depends exclusively on $\beta$, while MIDAS has a much more flexible functional form for the weights on past squared returns. When directly comparing GARCH and MIDAS weights, GARCH weights always decay much faster than MIDAS weights. This is a very important point. The persistence of the estimated GARCH variance process is lower than that of MIDAS ${ }^{10}$.

\section{The Risk-Return Trade-off under Asymmetric MIDAS}

It is well known that variance is not only persistent, but also increases more after negative than positive shocks. Recognizing this asymmetric behavior does not help to explain the risk-return relationship under the GARCH framework. In this section, we extend our previous analysis to test the risk-return trade-off under the asymmetric

\footnotetext{
${ }^{10}$ See GSV (2004) for details and also for a comparison with the rolling window approach to forecasting variance.
} 
MIDAS proposed by GSV (2004a). This estimator which incorporates the differential effect of positive and negative shocks in conditional variance is given by:

$$
\operatorname{Var}_{t}^{\text {amidas }}\left(R_{m t+1}\right)=22\left[\theta \sum_{d=0}^{D} \omega\left(d ; k_{1}^{-}, k_{2}^{-}\right) I_{t-d}^{-} r_{m t-d}^{2}+(2-\theta) \sum_{d=0}^{D} \omega\left(d ; k_{1}^{+}, k_{2}^{+}\right) I_{t-d}^{+} r_{m t-d}^{2}\right]
$$

where $\theta, k_{1}^{-}, k_{2}^{-}, k_{1}^{+}$and $k_{2}^{+}$are parameters to be estimated jointly with $\mu$ and $\gamma$ in the mean equation, $1_{t-d}^{-}$is an indicator function for $\left\{r_{t-d}<0\right\}, 1_{t-d}^{+}$denotes the indicator function for $\left\{r_{t-d} \geq 0\right\}$ and $\theta$ is in the interval $(0,2)$ and controls the total weight of negative shocks on the conditional variance ${ }^{11}$.

Table 3 reports the estimated coefficients of the relationship between market excess return and risk of equation (8) with the conditional variance estimators based on expression (11). The estimated risk aversion coefficients are always positive and significant except in the case of the United Kingdom where we observe a positive but insignificant coefficient. The significant risk aversion estimates for all other four equity indices ranges from 6.55 for Eurostoxx 50 to 2.98 for Germany. In contrast to the GARCH findings, recognizing the differential impact of negative and positive shocks does not change the sign of the risk-return trade-off. This confirms the results reported by GSV (2004a) for the US market, and increases confidence in the result that asymmetries are consistent with a positive risk aversion coefficient. This is a very comforting result. We may conclude that overall there is a positive relationship between expected market excess return and conditional variance ${ }^{12}$.

The results regarding the weight function are also interesting. Table 3 contains the percentages of weights for different day intervals for both negative and positive weights, and Figure 3 plots the weight profiles. In the case of Eurostoxx 50 the impact of negative and positive shocks seems to be similar, and the weights are practically the

\footnotetext{
${ }^{11}$ As explained by GSV (2004a), a coefficient $\theta$ between zero and two guarantees that the total weights add up to one, since the indicator functions are mutually exclusive and, therefore, each of the negative and positive weights adds up to one. When $\theta=1$, equal weight is placed on positive and negative shocks. ${ }^{12}$ As suggested by Scruggs (1998), market imperfections such as taxes, transaction costs or preferred habitats might explain the significance of some of the constant terms in the risk-return relationship.
} 
same. Surprisingly, the persistence of variance is much lower when asymmetric shocks are incorporated than in the previous case. For France negative shocks have a strong impact on conditional variance but the impact is transitory. On the other hand, positive shocks have a smaller effect, but their impact persists for much longer. This profile is similar to the one found for the US market by GSV (2004a). However, once again there are clear differences between equity indices. Germany and Spain have positive shocks with an immediate effect on conditional variance, but it is the negative shock which is more persistent. The United Kingdom has hump-shaped weights for both negative and positive shocks. The weighting coefficient, $\theta$, is always less than one which implies that positive shocks have a greater overall effect on conditional variances for European equity indices than negative shocks do.

The key finding in the asymmetric MIDAS specification is that the persistence of negative and positive shocks may be quite different. This is clearly observed when data for several equity indices are used as in Table 3 and Figure 3. Models such as those in the GARCH family, which by construction do not allow for differences in the persistence of positive and negative shocks may not be able to adequately capture the dynamics of conditional variance, and therefore may easily fail to obtain a positive riskreturn trade-off ${ }^{13}$.

To further understand the importance of asymmetric effects, the (in-sample) forecasted annualized volatilities for symmetric and asymmetric MIDAS respectively displayed against the realized annualized volatility are plotted in Figures 4 and 5. Although the performance of both MIDAS specifications is quite impressive, it seems clear that asymmetric MIDAS is more successful at capturing periods of extreme volatility. From visual inspection of the conditional volatility process, asymmetric MIDAS produces the best forecasts of realized volatility.

\footnotetext{
${ }^{13}$ Recall that under GARCH positive and negative shocks decay at the same rate given by $\beta$.
} 


\section{The Risk-Return Trade-off under Bivariate Symmetric MIDAS}

As discussed in the introduction, when the investment opportunity set changes over time, the intertemporal asset pricing model can be written as in equation (2) assuming that a state variable $Z_{t}$ describes the time-varying behavior of available investments. If changing interest rates captures the opportunity set, then long-term government bond returns are a natural instrument for hedging against adverse shifts in the investment set. In this section, we employ excess returns on long-term government bonds from our four countries, and the corresponding equally-weighted bond portfolio return constructed with the same countries as the second variable in a two-factor asset pricing model ${ }^{14}$. The bivariate MIDAS can be written as:

$$
\begin{aligned}
& R_{m t+1}=\mu_{m}+\gamma \operatorname{Var}_{t}^{\text {midas }}\left(R_{m t+1}\right)+\lambda \operatorname{Cov}_{t}^{\text {midas }}\left(R_{m t+1}, R_{b t+1}\right)+\varepsilon_{m t+1} \\
& R_{b t+1}=\mu_{b}+\varepsilon_{b t+1} \\
& \operatorname{Var}_{t}^{\text {midas }}\left(R_{m t+1}\right)=22 \sum_{d=0}^{D} \omega_{m}\left(d ; k_{1}, k_{2}\right) r_{m t-d}^{2} \\
& \operatorname{Var}_{t}^{\text {midas }}\left(R_{b t+1}\right)=22 \sum_{d=0}^{D} \omega_{b}\left(d ; \phi_{1}, \phi_{2}\right) r_{b t-d}^{2} \\
& \omega_{m}\left(d ; k_{1}, k_{2}\right)=\frac{\exp \left(k_{1} d+k_{2} d^{2}\right)}{\sum_{i=0}^{D}\left(k_{1} i+k_{2} i^{2}\right)} \\
& \omega_{b}\left(d ; \phi_{1}, \phi_{2}\right)=\frac{\exp \left(\phi_{1} d+\phi_{2} d^{2}\right)}{\sum_{i=0}^{D}\left(\phi_{1} i+\phi_{2} i^{2}\right)} \\
& \operatorname{Cov}_{t}^{\text {midas }}\left(R_{m t+1}, R_{b t+1}\right)=\operatorname{Vol}_{t}^{\text {midas }}\left(R_{m t+1}\right) x \operatorname{Vol}_{t}^{\text {midas }}\left(R_{b t+1}\right) x \rho_{m b}\left(R_{m t+1}, R_{b t+1}\right)
\end{aligned}
$$

\footnotetext{
${ }^{14}$ GSV (2004a) add some exogenous variables to the simple MIDAS equation to test the risk-return tradeoff with additional predictive variables but they do not test the two-factor asset pricing model in a bivariate MIDAS framework.
} 
where $R_{b t+1}$ is the excess return of the long-term government bond portfolio, $\rho_{m b}$ is the correlation coefficient between the equity index excess return and the bond portfolio excess return, and the parameter set to be estimated is $\Theta=\left\{\mu_{m}, \mu_{b}, \gamma, \lambda, k_{1}, k_{2}, \phi_{1}, \phi_{2}, \rho_{m b}\right\}$. As in the case of the univariate MIDAS, the bivariate model is estimated by nonlinear least squares.

Table 4 contains the results which are somewhat contradictory. The risk aversion coefficient remains positive but significantly different from zero only for two indices, namely Eurostoxx50 and the German DAX index. Overall across countries, there is weak evidence of a positive partial relationship between risk and return. This suggests that the explanatory power of the forecasted variance for returns is not orthogonal to the additional covariance between equity returns and a hedging instrument represented by bond excess returns. At the same time, we may interpret the $\lambda$ coefficient in the mean equation as significantly different from zero for four out of five indices suggesting that more than one state variable is necessary to fully explain the relationship between risk and return along the lines argued by Scruggs (1998). Interpreting these results in terms of our objective of distinguishing between the wrong specification of the model and the wrong dynamics for conditional variances, we may conclude that both factors are important in explaining the failure in previous literature to find a positive risk-return trade-off.

However, a closer interpretation of the reported evidence casts doubts on the validity of bond returns as a hedging instrument once the process of conditional variance is determined by the MIDAS variance equations. The coefficient associated with the covariance term in the mean equation has the same sign as the correlation coefficient between equity returns and bond returns. This is disturbing and may suggest that bond returns do not play the hedging instrument role assumed by the model. In principle, we should expect a positive elasticity of marginal utility of wealth with respect to bond returns. Given that marginal utility of wealth and expected returns are inversely related, investors should require a lower market return when the correlation between bonds and equity returns is positive and high. However, in the case of Germany the sign of the estimate of $\lambda$ indicates that the elasticity of marginal utility of wealth with respect to bond returns is negative to be consistent with the negative correlation between equity 
and bond returns. The opposite argument applies to Eurostoxx50, France and the United Kingdom.

One potential source of estimating biases may be the assumption of constant correlation between equity and bond returns imposed by the bivariate MIDAS estimation. The evidence reported by Cappiello, Engle and Sheppard (2004) show that both bonds and equities exhibit asymmetry in conditional correlation. Moreover, once the assumption of constant conditional correlation between market returns and bond returns is relaxed, Scruggs and Glabadanidis (2003) fail to replicate the earlier results reported by Scruggs (1998) on the risk-return relationship under a two-factor asset pricing model. Our results open a new debate on the risk-return trade-off with multiple state variables when the conditional variance dynamics is represented by MIDAS.

\section{Conclusions}

By using flexible weighting schemes that allow an optimal choice of estimation of the weights on lagged squared returns that produces the necessary persistence in conditional variance and by employing a differential impact on and persistence of negative and positive shocks, this paper finds a positive and significant relationship between expected market excess return and conditional variance on European equity indices. These results take advantage of the MIDAS regression framework proposed by GSV $(2003,2004 a)$ and extend their key evidence on US data to European data. The MIDAS estimator is also characterized by using data sampled at various frequencies. In this sense, our results confirm that the use of daily data and the flexibility of the MIDAS estimator provide the statistical power necessary to find a significant risk-return tradeoff.

At the same time, there is also some evidence in favor of the two-factor intertemporal capital asset pricing model. Although the results are clearly inconclusive in this respect, it seems that both a wrong specification of the asset pricing model and the wrong dynamics imposed on conditional variance explain the disturbing historical evidence on the relationship between risk and return. 
Further research would clearly be welcomed. Asymmetric effects under bivariate MIDAS, the use of alternative hedging instruments in multi-factor asset pricing models under MIDAS dynamics, asymmetric and time-varying correlation effects between equity and bond returns, and counter-cyclical risk aversion coefficients under preferences with habit persistence are candidates for an exciting future research agenda. 


\section{REFERENCES}

Alonso, F. and F. Restoy (1995), "La remuneración de la volatilidad en el mercado español de renta variable", Moneda y Crédito 200, 99-115.

Brandt, M. and Q. Kang (2004), "On the relationship between conditional mean and volatility for stock returns: A latent VAR approach", Working Paper, The Wharton School, University of Pennsylvania.

Brennan, M., A. Wang, and Y. Xia (2004), "Estimation and test of a simple model of intertemporal capital asset pricing", Working Paper, Anderson Graduate School of Management, UCLA.

Campbell, J. (1987), "Stock returns and the term structure", Journal of Financial Economics 18, 373-399.

Campbell, J. and L. Hentschel (1992), "No news is good news: An asymmetric model of changing volatility in stock returns”, Journal of Financial Economics 31, 281-318.

Capiello, L., R. Engle and K. Sheppard (2004), "Asymmetric dynamics in the correlations of global equity and bond returns", Working Paper, University of California at San Diego.

French, K., W. Schwert and R. Stambaugh (1987), "Expected stock returns and volatility”, Journal of Financial Economics 19, 3-29.

Ghysels, E., P. Santa-Clara and R. Valkanov (2003), "The MIDAS touch. Mixed data sampling regression models", Working Paper, Anderson School of Management, UCLA.

Ghysels, E., P. Santa-Clara and R. Valkanov (2004a), "There is a risk-return trade-off after all”, Journal of Financial Economics forthcoming. 
Ghysels, E., P. Santa-Clara and R. Valkanov (2004b), "Predicting volatility: Getting the most out of return data sampled at different frequencies", Journal of Econometrics forthcoming.

Ghysels, E., P. Santa-Clara, A. Sinko and R. Valkanov (2004), "MIDAS regressions: Further results and new directions", Working Paper, Anderson School of Management, UCLA.

Glosten, L., R. Jagannatham and D. Runkle (1993), "On the relation between the expected value and the volatility of the nominal excess return on stocks", Journal of Finance 48, 1779-1801.

Green, W. (1998), “Econometric Analysis” Third Edition, Prentice Hall.

Guo, H. (2004), "Does stock market volatility forecast returns? The international evidence", Working Paper Series, The Federal Reserve Bank of St. Louis, Research Division.

Guo, H. and R. Whitelaw (2003), "Uncovering the risk-return relation in the stock market", Working Paper Series, FIN-03-021, Stern School of Business, New York University.

Harvey, C. (2001), “The specification of conditional expectations”, Journal of Empirical Finance 8, 573-638.

Judge, G., W. Griffith, R. Hill, H. Lutkepohl and T. Lee (1985), "The theory and practice of Econometrics”, Second Edition, John Wiley \& Sons.

Lettau, M. and S. Ludvigson (2001), "Consumption, aggregate wealth and expected stock returns", Journal of Finance 56, 815-849.

Lettau, M. and S. Ludvigson (2003), "Measuring and modeling variation in the riskreturn trade-off', in Yacine Aït-Sahalia and Lars P. Hansen, ed.: Handbook of Financial Econometrics, North Holland. 
Merton, R. (1973), An intertemporal capital asset pricing model”, Econometrica 41, 867-887.

Nelson, D. (1991), The variability of the market factor of the New York Stock Exchange”, Journal of Business 46, 434-453.

Santa-Clara, P. and S. Yan (2004), "Jump and volatility risk and risk premia: A new model and lessons from S\&P 500 options", Working Paper, Anderson School of Management, UCLA.

Scruggs, J. (1998), "Resolving the puzzling intertemporal relation between the market risk premium and conditional market variance: A two-factor approach", Journal of Finance 53, 575-603.

Scruggs, J. and P. Glabadanidis (2003), "Risk premia and the dynamic covariance between stock and bond returns", Journal of Financial and Quantitative Analysis" 38, 295-316. 


\section{Table 1}

The Risk-Return Trade-off in Europe under GARCH Specifications

The table shows estimates of the risk-return trade-off (3) with the GARCH and EGARCH estimators of conditional variance given by expressions (4) and (5). The coefficients and corresponding t-statistics (in parentheses) are shown for the entire sample monthly from 1989:01 to 2003:12. The t-statistics are computed using Bollerslev-Wooldridge standard errors.

\begin{tabular}{|c||c|c|c|}
\hline \multirow{2}{*}{ European Indices } & \multicolumn{2}{|c|}{ Risk Aversion Coefficients } & $\begin{array}{c}\text { Asymmetric } \\
\text { Coefficients }\end{array}$ \\
\cline { 2 - 4 } & GARCH & EGARCH & EGARCH \\
\hline \hline Eurostoxx50 & 4.930 & 4.966 & -0.078 \\
& $(1.434)$ & $(1.292)$ & $(-0.781)$ \\
France & 1.559 & -1.202 & -0.207 \\
& $(0.512)$ & $(-0.848)$ & $(-2.674)$ \\
Germany & -1.274 & -2.790 & -0.225 \\
& $(-0.503)$ & $(-0.932)$ & $(-3.281)$ \\
Spain & 2.436 & -1.195 & -0.202 \\
& $(0.459)$ & $(-0.345)$ & $(-1.833)$ \\
United Kingdom & 1.543 & -1.394 & -0.301 \\
& $(0.233)$ & $(-0.420)$ & $(-4.111)$ \\
\hline
\end{tabular}


Table 2

The Risk-Return Trade-off in Europe under Symmetric MIDAS Specification

The table shows estimates of the risk-return trade-off (3) with the symmetric MIDAS estimator of conditional variance given by expressions (9) and (10). Daily returns are used in the construction of the conditional variance estimator, and monthly returns in the estimation of the risk-return trade-off parameter (the coefficient of relative risk aversion $\gamma$ ). The coefficients and corresponding t-statistics (in parentheses) are shown for the entire mixed sample of daily and monthly returns from 1988:01 to 2003:12. The t-statistics are computed using the asymptotic standard errors of nonlinear least square estimators, and the R-square quantifies the explanatory power of the symmetric MIDAS variance estimator in predictive regressions for returns.

\begin{tabular}{|c|c|c|c|c|c|}
\hline \multicolumn{6}{|c|}{ Estimates under Symmetric Midas } \\
\hline Parameters & Eurostoxx 50 & France & Germany & Spain & $\begin{array}{c}\text { United } \\
\text { Kingdom }\end{array}$ \\
\hline$\mu$ & $\begin{array}{c}-0.00201 \\
(-0.261)\end{array}$ & $\begin{array}{c}-0.01133 \\
(-1.571)\end{array}$ & $\begin{array}{c}-0.01174 \\
(-1.429)\end{array}$ & $\begin{array}{c}-0.00937 \\
(-1.254)\end{array}$ & $\begin{array}{c}-0.00517 \\
(-1.080)\end{array}$ \\
\hline$\gamma$ & $\begin{array}{c}4.813 \\
(3.191)\end{array}$ & $\begin{array}{c}2.568 \\
(1.915)\end{array}$ & $\begin{array}{c}2.217 \\
(1.687)\end{array}$ & $\begin{array}{c}2.188 \\
(1.539)\end{array}$ & $\begin{array}{c}1.533 \\
(1.130)\end{array}$ \\
\hline$k_{1}$ & 0.00284 & 0.01249 & 0.00857 & 0.04641 & 0.21056 \\
\hline$k_{2}$ & -0.00014 & -0.00117 & -0.00009 & -0.00193 & -0.00723 \\
\hline $\begin{array}{l}\% \text { weights } \\
\text { days } 1-5\end{array}$ & 5.9 & 15.5 & 4.3 & 13.0 & 8.1 \\
\hline $\begin{array}{l}\% \text { weights } \\
\text { days } 6-30\end{array}$ & 29.0 & 64.6 & 23.4 & 69.3 & 88.2 \\
\hline $\begin{array}{l}\% \text { weights } \\
\text { days }>30\end{array}$ & 65.1 & 19.9 & 72.3 & 17.7 & 3.7 \\
\hline$R^{2}$ & 0.165 & 0.027 & 0.021 & 0.017 & 0.009 \\
\hline
\end{tabular}


Table 3

The Risk-Return Trade-off in Europe under Asymmetric MIDAS Specification The table shows estimates of the risk-return trade-off (3) with the asymmetric MIDAS estimator of conditional variance given by expression (11). Daily returns are used in the construction of the conditional variance estimator, and monthly returns in the estimation of the risk-return trade-off parameter (the coefficient of relative risk aversion $\gamma$ ). The coefficients and corresponding t-statistics (in parentheses) are shown for the entire mixed sample of daily and monthly returns from 1988:01 to 2003:12. The t-statistics are computed using the asymptotic standard errors of nonlinear least square estimators, and the R-square quantifies the explanatory power of the asymmetric MIDAS variance estimator in predictive regressions for returns.

\begin{tabular}{|c|c|c|c|c|c|}
\hline \multicolumn{6}{|c|}{ Estimates under Asymmetric Midas } \\
\hline Parameters & Eurostoxx 50 & France & Germany & Spain & $\begin{array}{c}\text { United } \\
\text { Kingdom }\end{array}$ \\
\hline$\mu$ & $\begin{array}{c}-0.02863 \\
(-3.680)\end{array}$ & $\begin{array}{c}-0.01324 \\
(-1.727)\end{array}$ & $\begin{array}{l}-0.02007 \\
(-2.754)\end{array}$ & $\begin{array}{c}-0.01505 \\
(-2.082)\end{array}$ & $\begin{array}{c}-0.00554 \\
(-1.136)\end{array}$ \\
\hline$\gamma$ & $\begin{array}{c}6.547 \\
(5.459)\end{array}$ & $\begin{array}{c}3.087 \\
(2.009)\end{array}$ & $\begin{array}{c}2.979 \\
(2.952)\end{array}$ & $\begin{array}{c}3.401 \\
(2.493)\end{array}$ & $\begin{array}{c}1.701 \\
(1.169)\end{array}$ \\
\hline$k_{1}(+)$ & -0.13928 & 0.00336 & -0.17180 & -0.10180 & 0.10179 \\
\hline$k_{2}(+)$ & -0.00010 & -0.00100 & -0.00122 & -0.00180 & -0.00678 \\
\hline $\begin{array}{c}\%+\text { weights } \\
\text { days } 1-5\end{array}$ & 50.6 & 16.5 & 61.1 & 48.5 & 22.4 \\
\hline $\begin{array}{c}\%+\text { weights } \\
6-30\end{array}$ & 48.0 & 63.7 & 38.7 & 50.9 & 76.9 \\
\hline $\begin{array}{c}\%+\text { weights } \\
>30\end{array}$ & 1.4 & 19.8 & 0.20 & 0.60 & 0.7 \\
\hline$k_{1}(-)$ & 0.01910 & 0.08842 & 0.04003 & 0.02120 & 0.39744 \\
\hline$k_{2}(-)$ & -0.01532 & -0.01912 & -0.00212 & -0.00235 & -0.01052 \\
\hline $\begin{array}{c}\% \text { - weights } \\
\text { days } 1-5\end{array}$ & 57.0 & 52.9 & 15.5 & 21.1 & 1.6 \\
\hline $\begin{array}{c}\% \text { - weights } \\
\text { days } 6-30\end{array}$ & 43.0 & 47.1 & 71.6 & 72.0 & 92.2 \\
\hline $\begin{array}{c}\% \text { - weights } \\
\text { days }>30\end{array}$ & 0 & 0 & 12.9 & 6.9 & 6.2 \\
\hline$\theta$ & 0.122 & 0.538 & 0.163 & 0.299 & 0.617 \\
\hline$R^{2}$ & 0.366 & 0.041 & 0.085 & 0.054 & 0.012 \\
\hline
\end{tabular}




\section{Table 4}

\section{The Risk-Return Trade-off in Europe under Symmetric}

\section{Bivariate MIDAS Specification}

The table shows estimates of the risk-return trade-off under the stochastic opportunity set with the symmetric bivariate MIDAS estimator of conditional variance given by expressions in (12). Daily returns are used in the construction of the conditional variance estimator, and monthly returns in the estimation of the risk-return trade-off parameters (the coefficient of relative risk aversion $\gamma$, and the hedging parameter 2). The coefficients and corresponding t-statistics (in parentheses) are shown for the entire mixed sample of daily and monthly returns from 1988:01 to 2003:12. The t-statistics are computed using the asymptotic standard errors of nonlinear least square estimators, and the R-square quantifies the explanatory power of the MIDAS variance estimator in predictive regressions for returns.

\begin{tabular}{|c|c|c|c|c|c|}
\hline \multicolumn{6}{|c|}{ Estimates under Symmetric Bivariate Midas } \\
\hline \hline Parameters & Eurostoxx50 & France & Germany & Spain & $\begin{array}{c}\text { United } \\
\text { Kingdom }\end{array}$ \\
\hline \hline$\mu$ & -0.01765 & -0.01302 & -0.01163 & -0.01756 & -0.01396 \\
& $(-1.771)$ & $(-1.843)$ & $(-1.142)$ & $(-1.764)$ & $(-1.998)$ \\
$\gamma$ & 5.737 & 2.378 & 5.109 & 1.180 & 1.406 \\
& $(1.996)$ & $(1.214)$ & $(2.040)$ & $(0.759)$ & $(0.651)$ \\
$\lambda$ & 18.882 & 18.338 & -28.380 & 10.070 & 10.111 \\
& $(2.479)$ & $(1.893)$ & $(-2.191)$ & $(1.164)$ & $(1.686)$ \\
$\rho\left(R_{m}, R_{b t}\right)$ & 0.013 & 0.207 & -0.023 & 0.224 & 0.330 \\
& $(0.134)$ & $(2.478)$ & $(-0.329)$ & $(2.605)$ & $(3.427)$ \\
& & & & & \\
$R^{2}$ & 0.238 & 0.022 & 0.028 & 0.025 & 0.025 \\
\hline
\end{tabular}


Figure 1

Weighting Shapes

Case 1: $k_{1}<0, k_{2}>0 \Rightarrow d^{*}>0, \bar{d}>d *$ and $f^{\prime \prime}>0($ min)

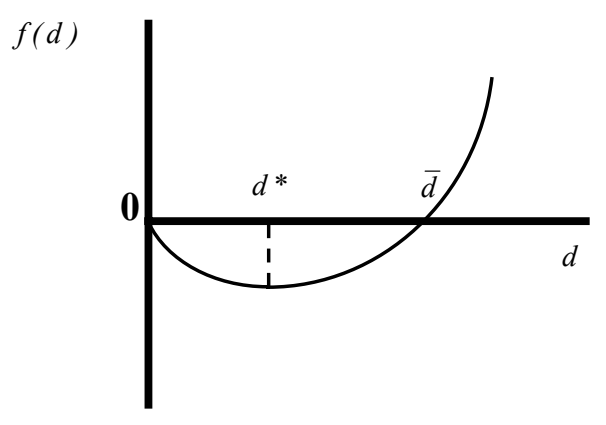

$$
\omega(d)=e^{f(d)} / \sum_{d} \omega(d)
$$

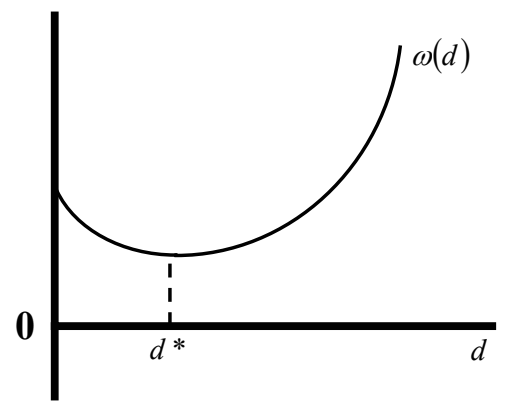

Case 2: $k_{1}>0, k_{2}<0 \Rightarrow d^{*}>0, \bar{d}>d *$ and $f^{\prime \prime}<0(\max )$
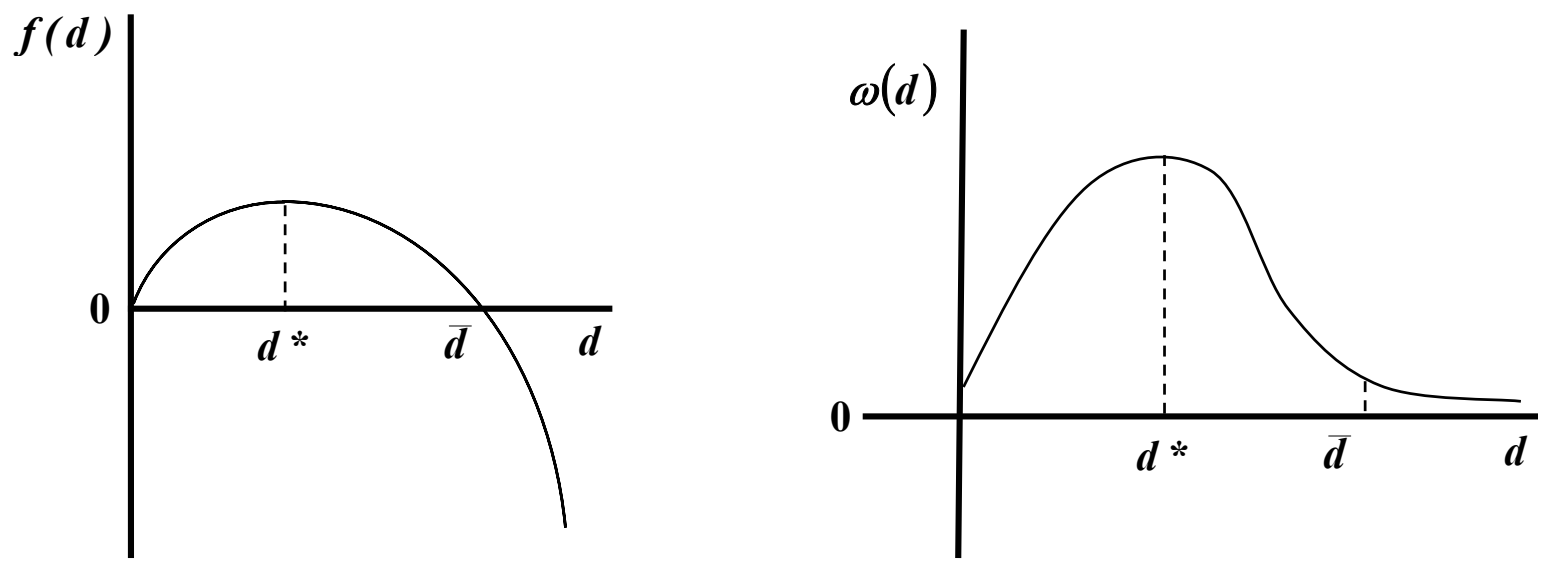
Case 3: $k_{1}<0, k_{2}<0 \Rightarrow d^{*}<0, \bar{d}<d^{*}$ and $f^{\prime \prime}<0$ (max)
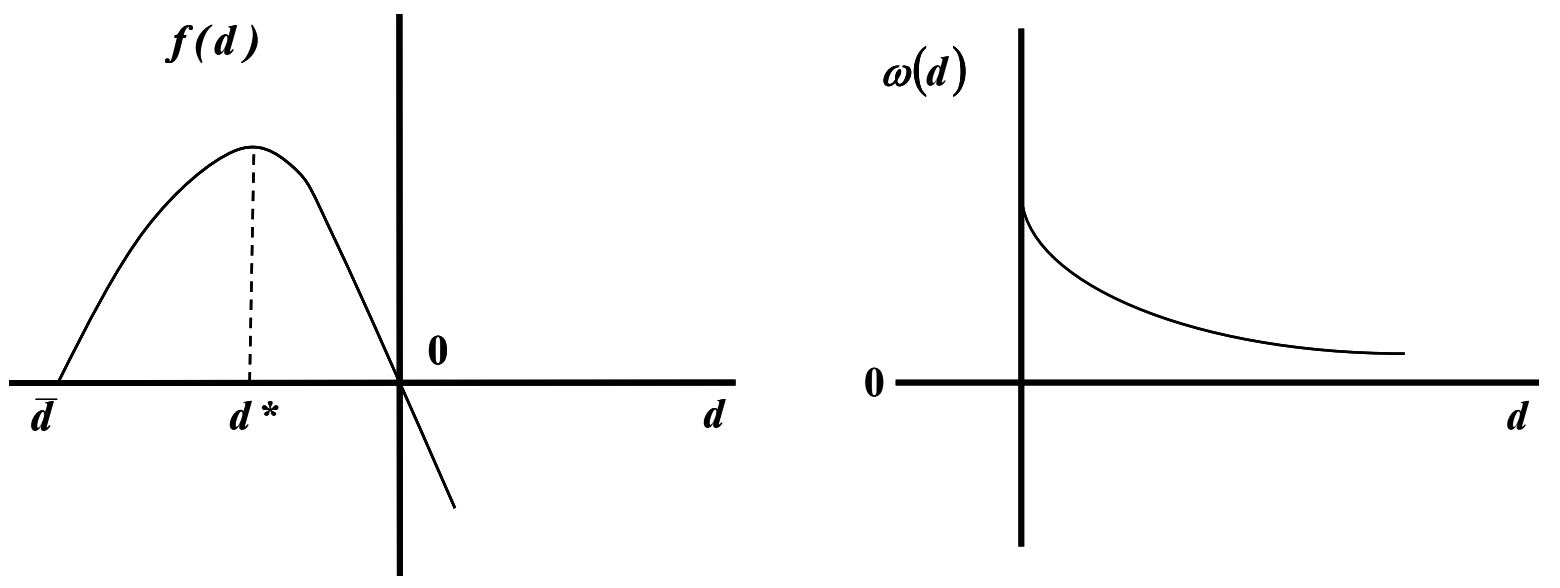

Case 4: $k_{1}>0, k_{2}>0 \Rightarrow d^{*}<0, \bar{d}<d *$ and $f^{\prime \prime}<0$ (min)
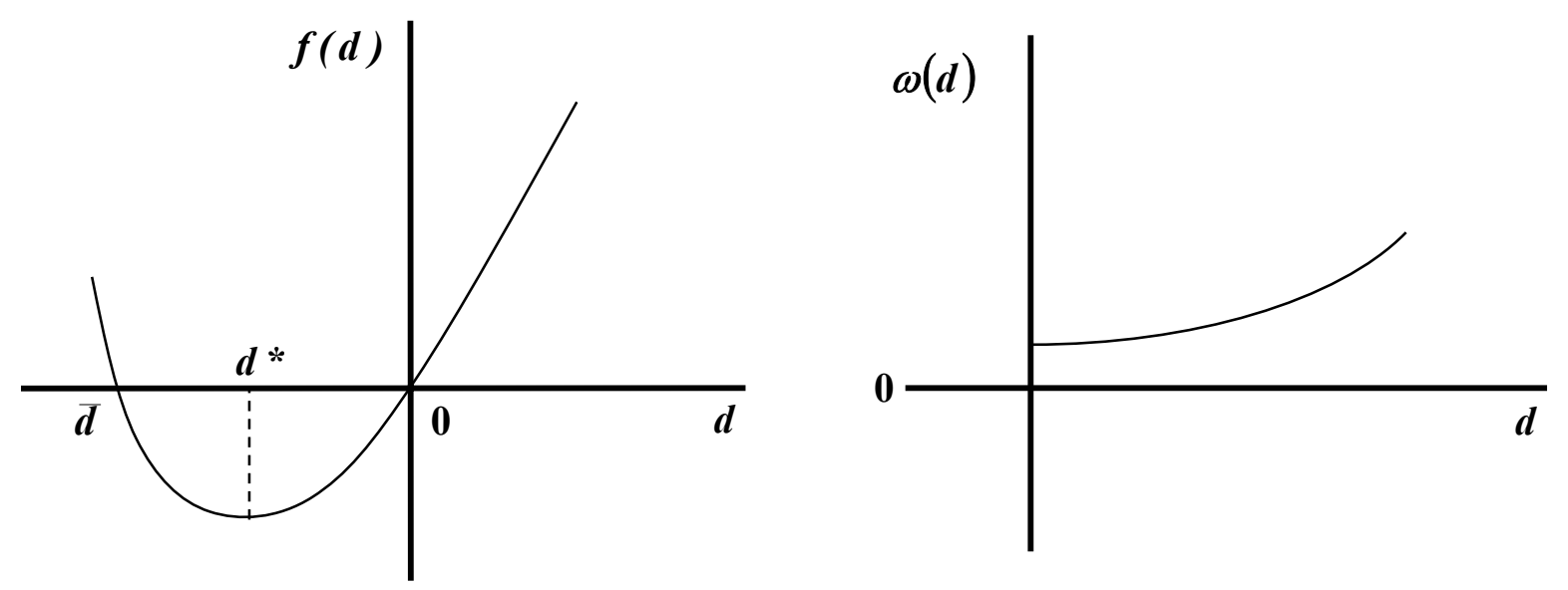
Figure 2

\section{Symmetric MIDAS Weights}

The figure plots the weights that the MIDAS estimator (9) and (10) places on lagged daily squared returns. The weights are calculated by substituting the estimated values of $k_{1}$ and $k_{2}$ of Table 2 into the weight function (10). The figure displays the weights for the entire sample from January 1988 to December 2003
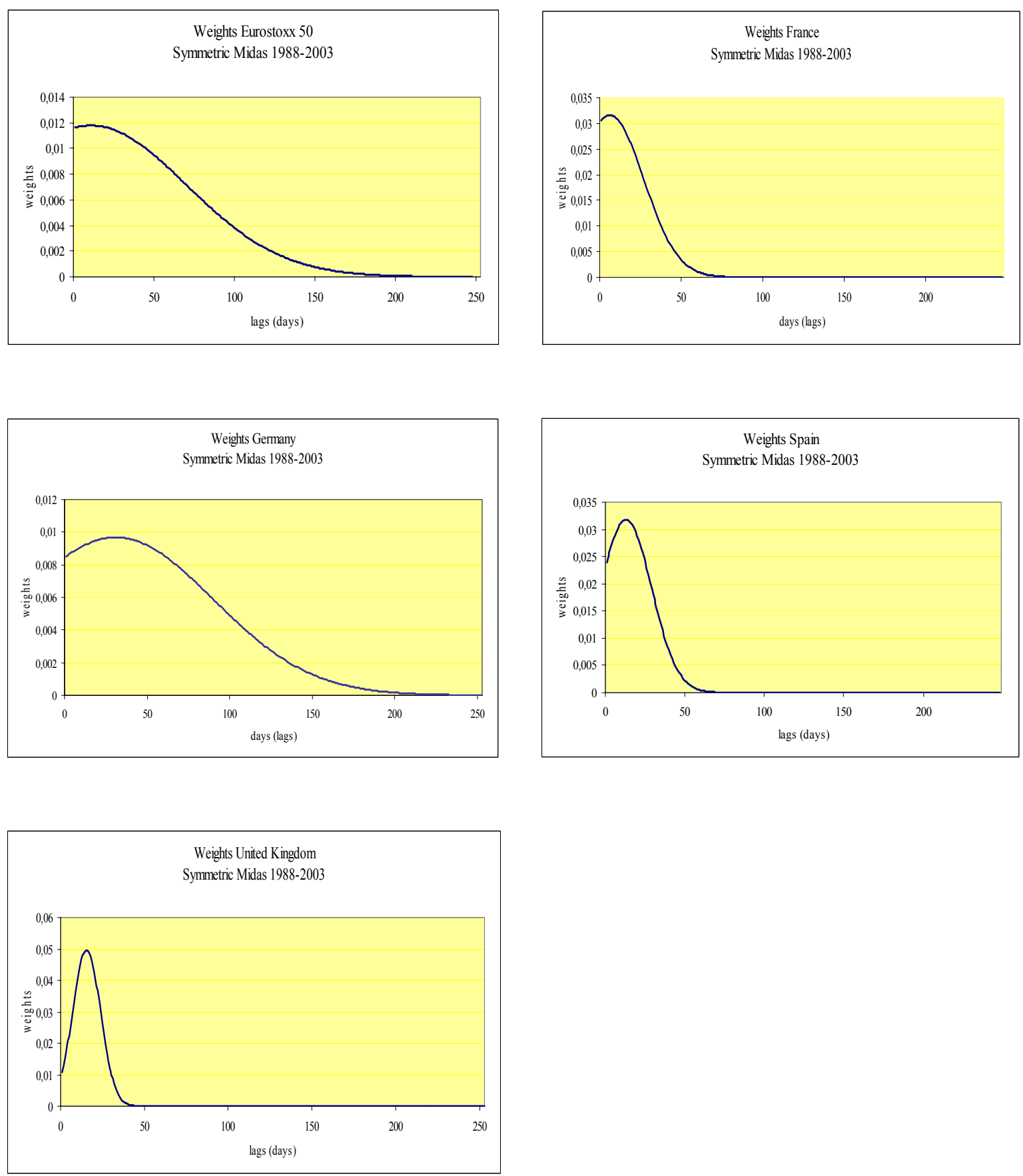


\section{Figure 3}

\section{Asymmetric MIDAS Weights}

The figure plots the weights that the MIDAS estimator (11) places on lagged daily squared returns conditional on the sign of the returns. The weights on the negative shocks are calculated by substituting the estimated values of $k_{1}^{-}$and $k_{2}^{-}$of Table 3 into the weight function (11), while the weights on the positive shocks are obtained by substituting the estimated values of $k_{1}^{+}$and $k_{2}^{+}$of Table 3 into the weight function (11). The total asymmetric weights, plotted using equation (11), take into account the weighted impact of asymmetries on conditional variance through the parameter $\theta$. The figure displays the weights for the entire sample from January 1988 to December 2003
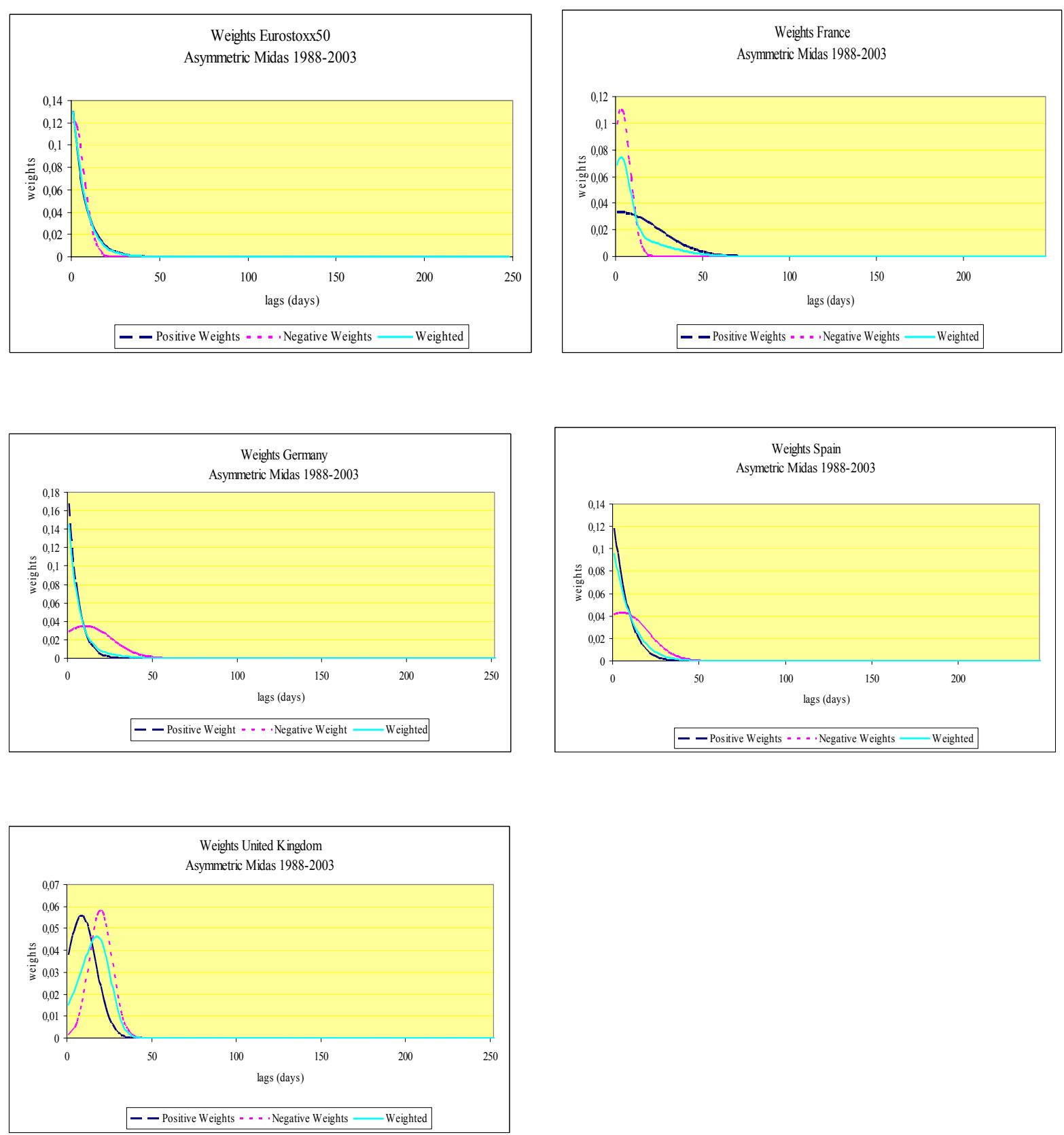


\section{Figure 4}

Symmetric MIDAS Conditional Volatilities

The figure plots the symmetric annualized conditional MIDAS volatility and the realized volatility. The figure displays the volatilities for the entire monthly sample from January 1989 to December 2003
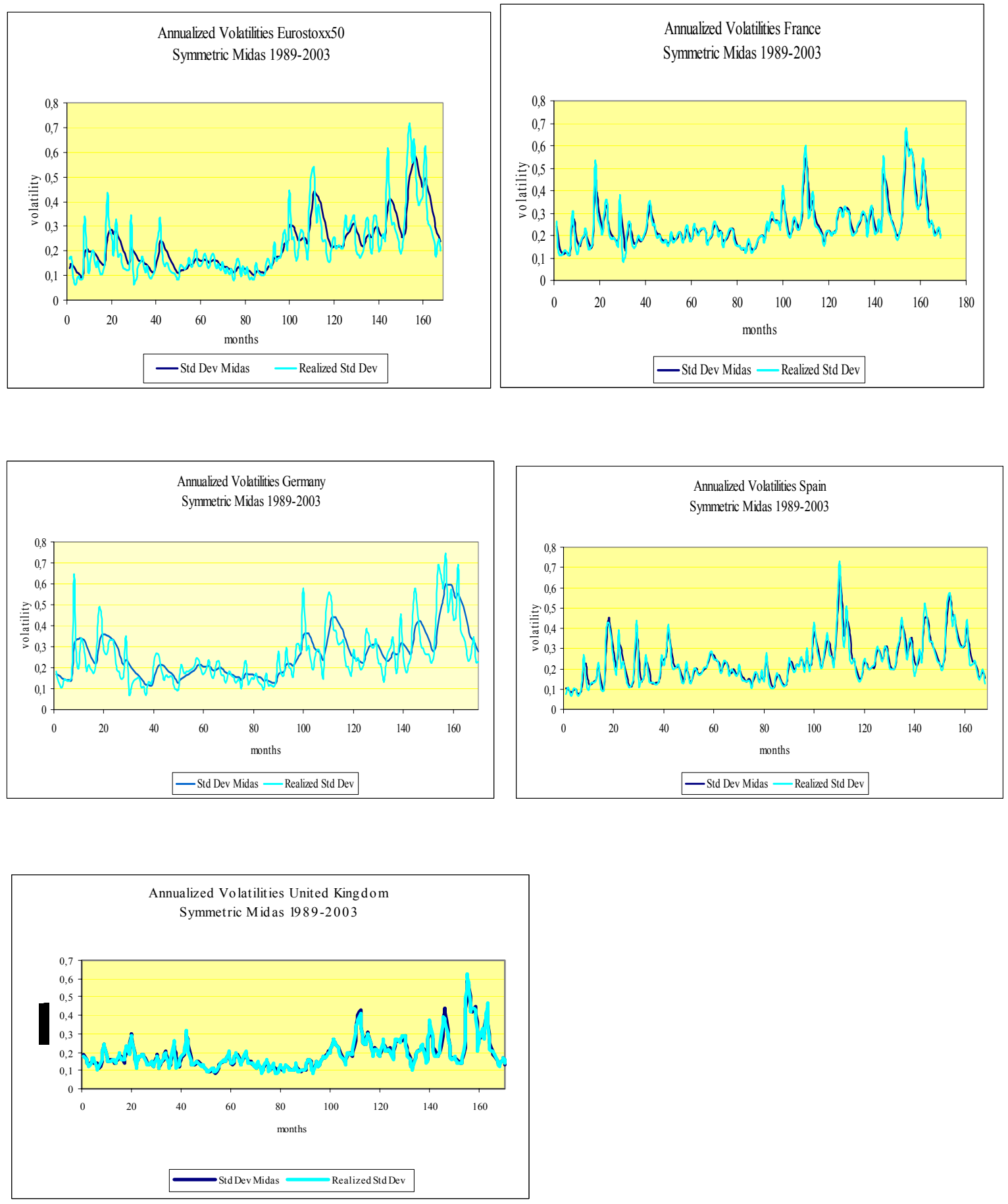


\section{Figure 5}

\section{Asymmetric MIDAS Conditional Volatilities}

The figure plots the asymmetric annualized conditional MIDAS volatility and the realized volatility. The figure displays the volatilities for the entire monthly sample from January 1989 to December 2003
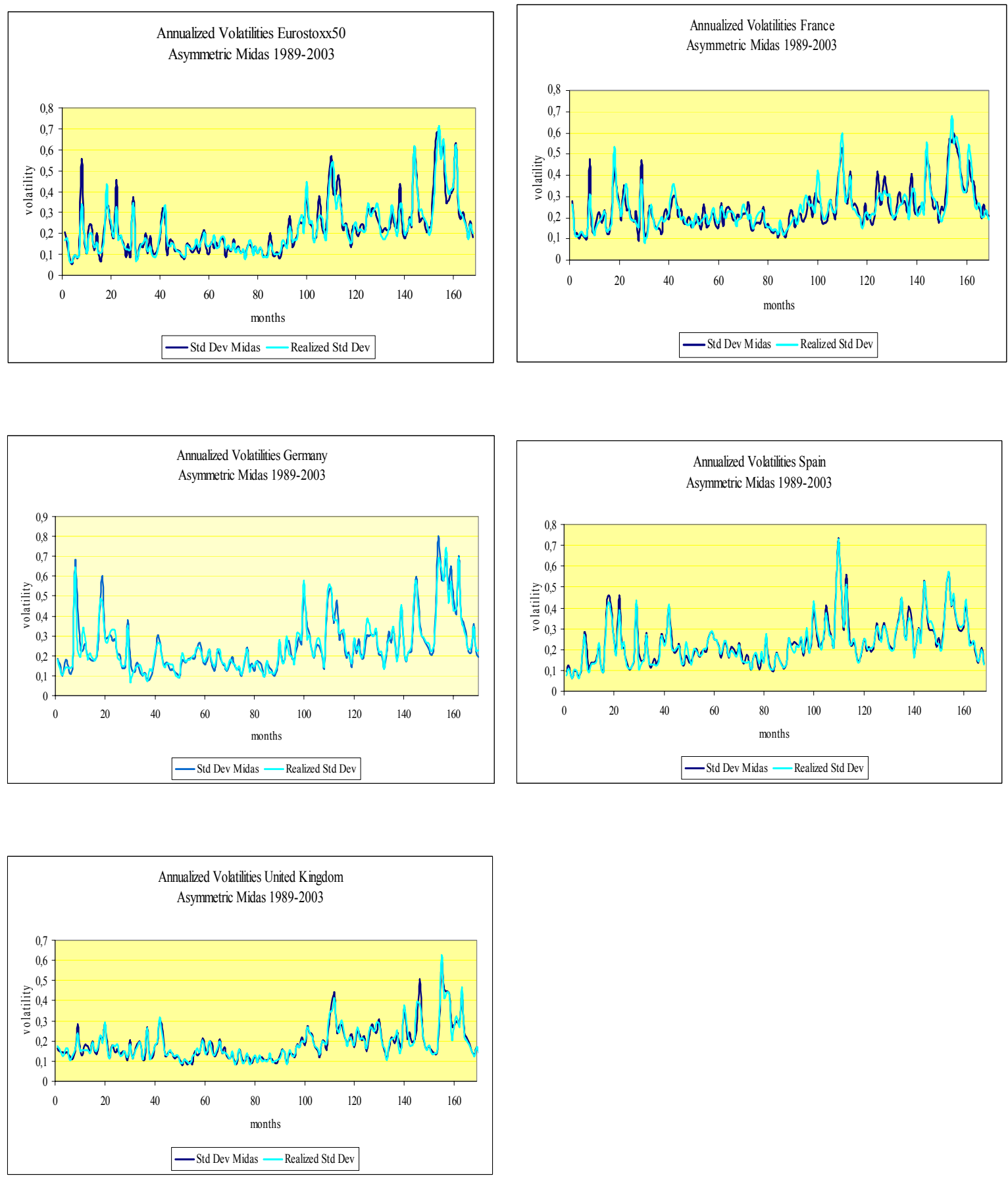